\title{
The Impact of Mast Cell Density on the Progression of Bone Disease in Multiple Myeloma Patients
}

\author{
Rodanthi Vyzoukaki ${ }^{a}$ George Tsirakis ${ }^{\text {e Constantina A. Pappa }}{ }^{d}$ \\ Maria Devetzoglou $^{b}$ Maria Tzardic Michael G. Alexandrakis ${ }^{a, b}$ \\ ${ }^{a}$ Hematology Laboratory, ${ }^{b}$ Hematology Department and 'Pathology Department, University Hospital of Heraklion, \\ and d Department of Internal Medicine, Venizelion Hospital of Heraklion, Heraklion, and eHematology Department, \\ General Hospital of Chania, Chania, Greece
}

\section{Key Words}

Cytokines · Mast cells $\cdot$ Multiple myeloma $\cdot$ Osteolysis

\begin{abstract}
Background: Osteolytic bone disease is a major hallmark in multiple myeloma (MM) progression and affects many patients. Several inflammatory cells are involved in MM progression. Among them, mast cells (MCs) accumulated in the bone marrow (BM) microenvironment are known to play an important role in the mechanism of neovascularization. Methods: In 52 newly diagnosed active MM patients, we measured BM MC density (MCD) using an immunohistochemical stain for tryptase, serum levels of matrix metalloproteinase-9 (MMP-9) and receptor activator of nuclear factor KB ligand (RANKL) by a solid-phase sandwich enzymelinked immunosorbent assay, along with urine levels of $\mathrm{N}$-terminal propeptide of procollagen type I (Ntx) by a competitive inhibition enzyme-linked immunosorbent assay, in various clinical stages and skeletal grades. Results: $M C D$, RANKL and Ntx were higher in MM patients. All values increased in association with both the clinical stage and skeletal grade. Furthermore, MCD correlated positively with MMP-9, RANKL and Ntx. Conclusions: Our data suggest that MCs may contribute to osteolytic processes during MM pro-
\end{abstract}

gression. Although the major role of MCs in tumor progression is to enhance angiogenesis, it seems that they may affect MM bone disease and may secrete a plethora of mediators that may directly and indirectly have an impact on osteolysis.

(c) 2016 S. Karger AG, Basel

\section{Introduction}

The progression of premalignant monoclonal gammopathy of undetermined significance to multiple myeloma (MM) remains a rather obscure process. Several aspects in MM growth, involving alterations in the bone marrow (BM) microenvironment, enhance this progression in complex manners. The interplay of the various versatile participants enhances a vicious cycle of self-renewal that, without external interventions, may lead to the dissemination of the disease. Increased angiogenesis and bone reabsorption, along with suppressed immune response of the host, are major hallmarks of disease progression [1].

Myeloma osteolytic bone disease is a malignant plasma cell attempt to create more space for their growth and can be considered the result of an impaired balance be-

\section{KARGER 125}

(c) 2016 S. Karger AG, Basel

$1018-2438 / 16 / 1684-0263 \$ 39.50 / 0$

E-Mail karger@karger.com

www.karger.com/iaa
Correspondence to: Prof. Michael G. Alexandrakis

Hematology Department, University Hospital of Heraklion

PO Box 1352

GR-71110 Heraklion (Greece)

E-Mail alexandm@med.uoc.gr 
tween osteoclasts, with increased activity, enhancing bone reabsorption, and osteoblasts, with decreased activity, reducing bone formation. The disruption of bone remodeling in MM is unique among other malignant bone diseases, causing skeleton-related events, hypercalcemia and morbidity. The dynamic interplay between myeloma cells and the BM microenvironment is the inaugural and driving force behind osteolytic MM disease. The study of this interplay has progressed significantly, and the disease pathology is becoming a more feasible therapeutic target. Nevertheless, this aspect of MM growth remains a major problem for MM patients [1,2].

Several inflammatory cells are involved in MM progression. Among them, mast cells (MCs) are accumulated in the BM microenvironment as a host response, displaying potential tumoricidal activity: myeloma cells secrete attractant mediators for MCs, but in turn they secrete several other factors involving MM growth. By these means, MC accumulation, although initially with antitumor potential, supports the dissemination of the disease $[3,4]$. We have already described that BM MC density (MCD) is correlated with International Staging System stages [5] and moreover with the proliferation rate of myeloma plasma cells [6]. These observations could be justified by the positive correlation with the angiogenic process that has been studied rather extensively since 1999 [7]. By these means, MCs may secrete various direct and indirect angiogenic factors and may also participate in vasculogenesis mimicry $[3,8,9]$. Nevertheless, since MCs may produce various versatile factors, it seems that their participation in MM growth is more complex.

The aim of this study is to estimate whether the degree of MC accumulation in MM BM is associated with the degree of osteolytic disease. Therefore, we estimated MCD in MM BM and tried to correlate it with the radiographic skeletal degree, along with circulating levels of known factors of bone disease, such as matrix metalloproteinase-9 (MMP-9), receptor activator of nuclear factor $\kappa \mathrm{B}$ ligand (RANKL), as well as with urine levels of $\mathrm{N}$ terminal propeptide of procollagen type I (Ntx).

\section{Material and Methods}

\section{Patients}

Fifty-two newly diagnosed patients with active MM (26 male and 26 female; median age 65 years, range $47-88$ years) were enrolled in the study. Patients with renal or liver impairment, a history of previous or current other malignancies, other BM diseases, HIV, uncontrolled infectious diseases, use of immunomodulatory drugs or incapability to consent, were excluded from the study.
According to the International Staging System, 12 patients were in stage I, 19 in stage II and 21 in stage III of the disease. The types of monoclonal proteins were: IgG in 30, IgA in 16 and light chain disease in 6 patients. Regarding bone disease, according to standard X-ray evaluation, following magnetic resonance imaging for patients with osteolyses or fractures, 15 had grade 0 (no lesions), 7 had grade 1 (1 single osteolysis or diffuse osteoporosis), 7 had grade 2 (2-4 osteolytic lesions) and 23 had grade 3 (>4 osteolytic lesions or bone fracture). None of the patients had received any kind of myeloma-related therapy prior to examination. Fifteen age- and sex-matched, healthy volunteers were used as controls. The study was performed in accordance with the ethical standards laid down in the 1964 Declaration of Helsinki. Informed consent for the study was obtained from all subjects, prior to their inclusion in the study.

\section{Methods}

MMP-9 and RANKL were measured on serum samples, which were stored at $-70^{\circ} \mathrm{C}$, after collection, and assayed at the end of the study, in order to avoid interassay variability. Serum levels of MMP-9 and RANKL were measured by the solid-phase sandwich enzyme-linked immunosorbent assay, employing monoclonal anti-MMP-9 (Quantikine, R\&D Systems, Minneapolis, Minn., USA) and anti-RANKL (BioVendor Laboratorni Medicina AS, Brno, Czech Republic), according to the manufacturers' instructions. Ntx in urine was measured by a competitive inhibition enzymelinked immunosorbent assay (Ostex International, Seattle, Wash., USA).

BM MCD was estimated using a monoclonal antibody to MC tryptase (Ab-2 of Thermo Scientific, clone AA1), as has been described elsewhere [5]. In each specimen, BM MCs were quantified in 3 areas (of neoplastic infiltration for the patients) containing the highest number of MCs (hot spots), in 10 high-power fields $(\times 400)$ for each hot spot separately. MCD was the mean percentage of positive staining of MCs calculated in the 3 hot spots for each specimen and expressed as MCs/ $0.0625 \mathrm{~mm}^{2}$.

\section{Statistical Analyses}

All measured parameters are expressed as means and standard deviations. Statistical comparison between MM and control groups was made using the nonparametric Mann-Whitney test. The nonparametric Kruskal-Wallis test and one-way analysis of variance were used to evaluate differences between disease stage groups. Correlation between the measured parameters was studied with Spearman's correlation (r). IBM SPSS Statistics 21.0 was used for statistical analysis. A level of 0.05 was set as significant.

\section{Results}

In patients with active MM, MCs were observed in areas both within paratrabecular regions and diffusely in the cellular marrow, and were isolated. Table 1 shows serum levels of MMP-9 and RANKL, urine levels of Ntx and BM MCD in MM patients and controls. Values for MCD, RANKL and Ntx were higher in MM patients $(\mathrm{p}<0.001)$. Table 2 displays data for each International Staging Sys- 
Table 1. BM MCD, serum levels of MMP-9 and RANKL, and urine levels of Ntx in MM patients and in healthy controls

\begin{tabular}{|c|c|c|c|}
\hline & $\begin{array}{l}\text { Patients } \\
(\mathrm{n}=52)\end{array}$ & $\begin{array}{l}\text { Controls } \\
(\mathrm{n}=15)\end{array}$ & $\mathrm{p}$ value \\
\hline MCD, MCs/0.0625 mm $\mathrm{mm}^{2}$ & $9.7 \pm 4.6$ & $1.6 \pm 0.6$ & $<0.001$ \\
\hline MMP-9, ng/ml & $126.1 \pm 90.9$ & $119.8 \pm 63.4$ & n.s. \\
\hline RANKL, pmol/l & $440.1 \pm 413.3$ & $21.5 \pm 13.7$ & $<0.001$ \\
\hline $\begin{array}{l}\text { Ntx, nmol BCE/ } \\
\text { mmol creatinine }\end{array}$ & $158.5 \pm 87.8$ & $31.9 \pm 4.8$ & $<0.001$ \\
\hline
\end{tabular}

Values are given as means $\pm \mathrm{SD}$. BCE $=$ Bone collagen equivalent; n.s. = not significant.
Table 2. BM MCD, serum levels of MMP-9 and RANKL, and urine levels of $\mathrm{Ntx}$ in International Staging System stages in active MM patients

\begin{tabular}{lccc}
\hline & $\begin{array}{l}\text { Stage I } \\
(\mathrm{n}=12)\end{array}$ & $\begin{array}{l}\text { Stage II } \\
(\mathrm{n}=19)\end{array}$ & $\begin{array}{l}\text { Stage III } \\
(\mathrm{n}=21)\end{array}$ \\
\hline MCD, MCs/0.0625 mm & $4.7 \pm 1.2$ & $8.2 \pm 2.1$ & $14.0 \pm 3.6$ \\
MMP-9, ng/ml & $50.6 \pm 32.4$ & $138.5 \pm 67.4$ & $157.8 \pm 112.5$ \\
RANKL, pmol/1 & $56.7 \pm 44.6$ & $218.8 \pm 91.9$ & $859.2 \pm 415.5$ \\
$\begin{array}{l}\text { Ntx, nmol BCE/ } \\
\quad \text { mmol creatinine }\end{array}$ & $50.3 \pm 24.5$ & $154.4 \pm 72.1$ & $224.1 \pm 55.5$ \\
\hline
\end{tabular}

Values are given as means $\pm \mathrm{SD} . \mathrm{BCE}=$ Bone collagen equivalent; $\mathrm{p}<0.001$ for all cases.

Table 3. BM MCD, serum levels of MMP-9 and RANKL, and urine levels of Ntx in radiographic skeletal grades of bone disease in active MM patients

\begin{tabular}{lcccc}
\hline & Grade 0 $(\mathrm{n}=15)$ & Grade 1 $(\mathrm{n}=7)$ & Grade 2 $(\mathrm{n}=7)$ & Grade 3 $(\mathrm{n}=23)$ \\
\hline MCD, MCs/0.0625 mm & & $7.4 \pm 4.6$ & $9.7 \pm 3.1$ & $12.3 \pm 4.0$ \\
MMP-9, ng/ml & $6.7 \pm 4.0$ & $59.9 \pm 28.9$ & $184.2 \pm 107.3$ & $163.5 \pm 90.2$ \\
RANKL, pmol/l & $69.6 \pm 28.9$ & $247.7 \pm 224.9$ & $376.8 \pm 359.9$ & $751.2 \pm 437.0$ \\
Ntx, nmol BCE/mmol creatinine & $62.2 \pm 74.5$ & $125.1 \pm 85.0$ & $173.4 \pm 54.8$ & $222.0 \pm 61.6$ \\
\hline
\end{tabular}

Values are given as means \pm SD. BCE $=$ Bone collagen equivalent; $\mathrm{p}<0.001$ for all cases.

tem stage, where it can be seen that all of them were increasing in parallel with disease stage $(\mathrm{p}<0.001)$. Table 3 shows values by skeletal grades, where it can also be seen that values increased with the skeletal progression $(\mathrm{p}<$ 0.001; fig. 1 for MCD).

Significant positive correlations were found between MCD with levels of MMP-9 $(r=0.384, p<0.005)$, RANKL $(\mathrm{r}=0.738, \mathrm{p}<0.0001)$ and $\mathrm{Ntx}(\mathrm{r}=0.634, \mathrm{p}<0.0001$; fig. 2 for RANKL and Ntx).

\section{Discussion}

MCs are present in most tissues where they mature and acquire their unique and heterogeneous features depending on the tissue microenvironment [10]. They can be activated after exposure to either an allergen or by other triggers, such as cytokines and neuropeptides, including corticotropin-releasing hormone $[11,12]$. Their activation can be enhanced by stem cell factor (SCF) and interleukin-33 (IL-33), being both considered 'sensors of cell injury' $[13,14]$. SCF is the ligand for KIT receptor, encoded by the c-kit gene. Several somatic mutations of c-kit have been implicated in various malignancies, including mastocytosis [10]. Upon activation, MCs can release a plethora of mediators, which includes: preformed mediators stored in their cytoplasmic granules, such as histamine, tryptase and other proteases, cytokines [tumor necrosis factor- $\alpha$ (TNF- $\alpha$ ), fibroblast growth factor (FGF), IL-4 and SCF] and proteoglycans (heparin, chondroitin sulfates) [10, 15]; neoformed or lipid mediators, products of phospholipase $\mathrm{A}_{2}$ activation, such as prostaglandins, leukotrienes and platelet-activating factor $[4,10,16]$, and neosynthesized mediators, produced and released upon transcriptional activation, such as IL-1, IL-5, IL-6, IL-8, IL-9, IL-13, IL-17, TNF- $\alpha$, transforming growth factor- $\beta$, FGF and vascular endothelial growth factor (VEGF) [4, 10, 17-19].

MCs seem to be some of the first inflammatory cells accumulating in developing tumors. It has been postulated that the initial stimulus for their accumulation in malignant infiltration areas, typically around blood vessels, originates from malignant cells, and their presence is part of the initial host response to malignancy $[4,8]$. 


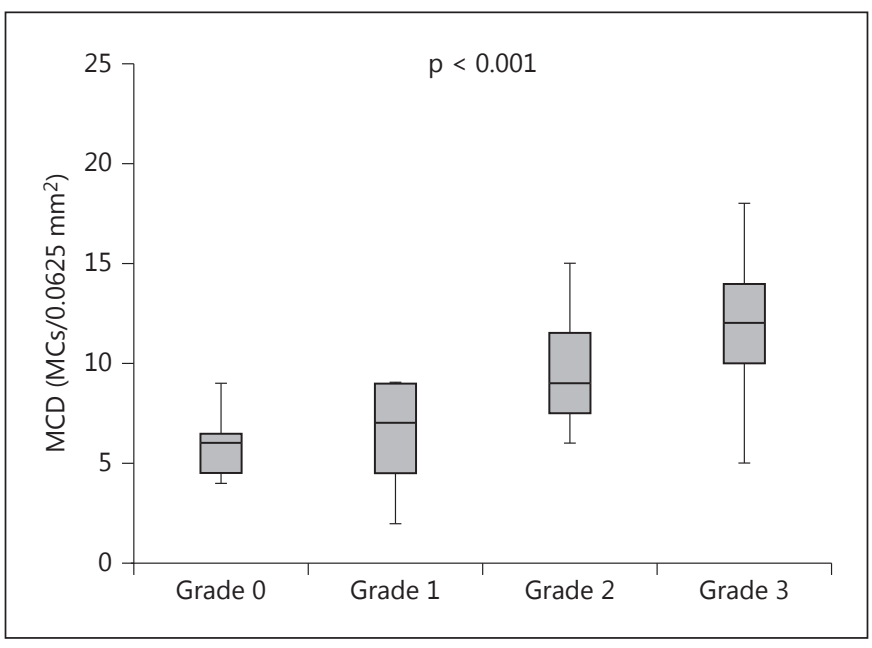

Fig. 1. BM MCD in radiographic skeletal grades of bone disease in active MM patients.

Among attractants, SCF, c-kit receptor, FGF-2, VEGF and platelet-derived growth factor are major mediators; there is a consequent release from MCs of inflammatory mediators, participating in tissue remodeling and immune suppression. By these means, MCs participate in tumor progression by realizing proangiogenic and mitogenic factors, suppressing immune surveillance and degrading the extracellular matrix (ECM) $[4,8,20]$.

There is a clear association of MCD with the angiogenic potential in several inflammations and malignant diseases, suggesting that stimulation of angiogenesis is the most significant role of MCs to tumor growth. There is a well-studied participation of MCs in the MM angiogenic process, in terms of the correlation with BM microvascular density $[3,4,6-8]$. This contribution is based on the production by MCs of several direct and indirect angiogenic factors, such as tryptase, chymase, heparin, histamine, transforming growth factor- $\beta$, TNF- $\alpha$, IL- 6 , IL- 8 , IL-17, IL-18, FGF-2 and VEGF. These mediators induce angiogenesis in several stages, such as degradation of the ECM, proliferation and migration of endothelial cells, formation and distribution of new vessels, synthesis of the ECM and pericyte mobilization $[4,21]$. In particular for tryptase, the predominant protease in MCs, it has been suggested to be critical for the initiation of angiogenesis, participating in several stages, such as degradation of the ECM and fibrinogen, activation of plasminogen, latent collagenase and metalloproteinases and dysfunction of the endothelial barrier [4]. Moreover, it has been postulated to be a potent mitogen for fibroblasts,

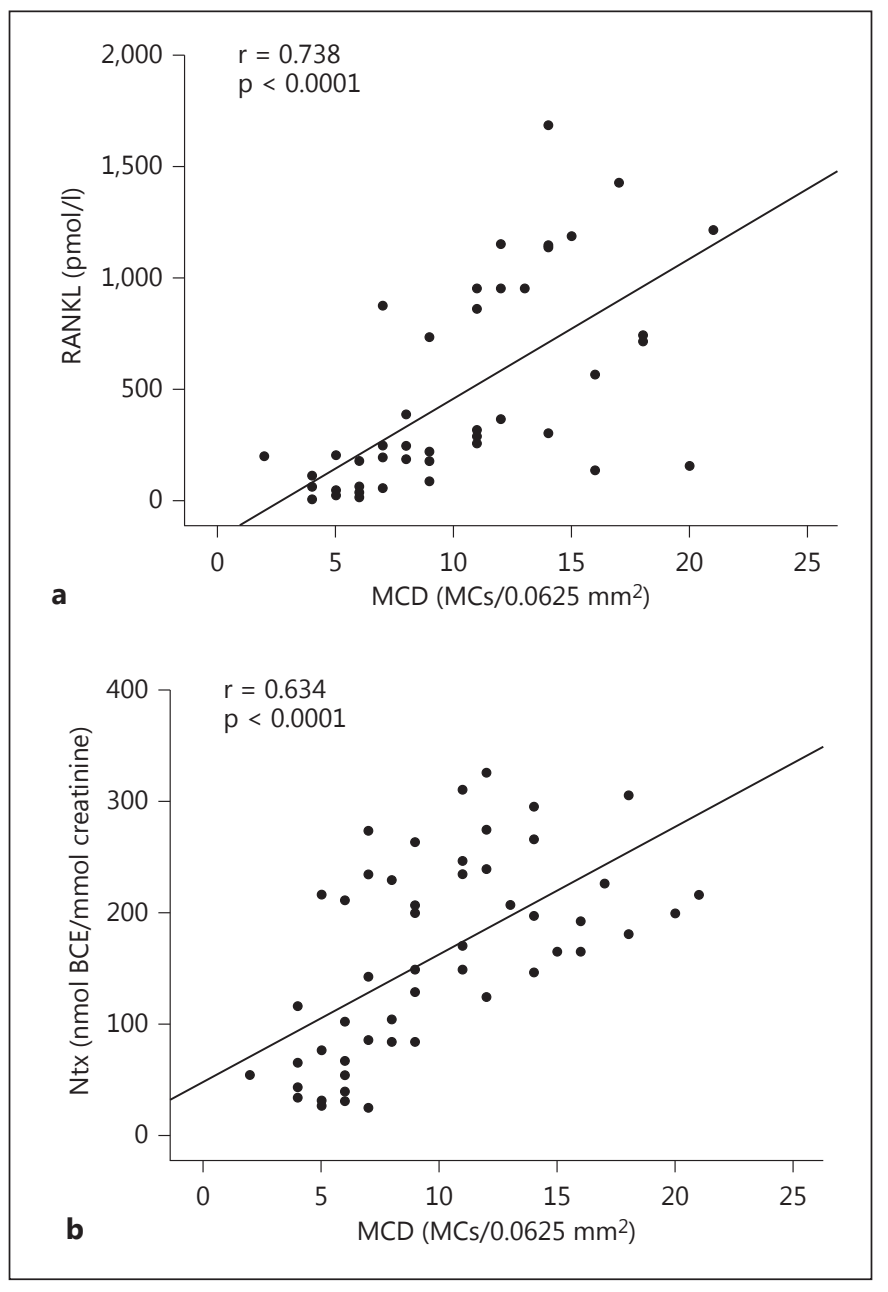

Fig. 2. Positive correlations between BM MCD with serum levels of RANKL (a) and urine levels of Ntx, estimated as nanomoles of bone collagen equivalent (BCE) per millimoles of creatinine (b).

smooth muscle and epithelial cells [22, 23]. Furthermore, it has been demonstrated that tryptase-positive MCs may participate in the neovascular wall, connected by a junctional system with the endothelial cells, without transdifferentiation into endothelial cells [9]. Another important cytokine secreted by MCs is IL-6, a major growth factor of myeloma plasma cells, with a central role in all aspects of MM progression. It has been reported that IL-6 also possesses a significant role in osteoporosis in mastocytosis patients as well [24]. Therefore, it is expected that BM MCD will increase in parallel with BM microvascular density. Among major angiogenic factors produced by MCs in MM is VEGF $[25,26]$.

In the present study we demonstrate that BM MCD in MM patients is correlated with radiographic skeletal 
grades. Although X-ray evaluation of MM bone disease is rather rough, with limited sensitivity compared to magnetic resonance imaging, especially for the low-grade cases, it offers an easy initial estimation. Our data suggests that when bone disease increases, and therefore is more easily estimated with radiographic imaging, there is an underlying increase in $\mathrm{MC}$ accumulation in $\mathrm{BM}$. This can be justified through the angiogenic process, since the major role of MCs is angiogenic progression which in turn is correlated with both disease activity and bone disease [27]. It can be hypothesized that the participation of MCs in osteolytic disease is indirect. On the other hand, there are several angiogenic procedures participating in osteolytic disease, such as degradation of the ECM. This observation is enhanced by the positive correlations of MCD with levels of MMP-9, and mainly with RANKL and Ntx observed in our study. The correlation with the cytokines seems to be mainly indirect, although MCs may secrete RANKL, since it is mainly secreted by myeloma cells. MCs also secrete IL-6, prostaglandin $\mathrm{D}_{2}$, TNF and tryptase, all of which potentially cause skeletal disease in MC disorders [10, 24, 28]. Moreover, MC tryptase may acti- vate latent metalloproteinases [4]. Similarly, the correlation of MCD with Ntx levels is also rather indirect, since its urine levels are among the most sensitive and specific biochemical markers of bone reabsorption, and therefore it represents the total osteoclastic activity [29]. To the best of our knowledge, this is the first report assessing the relationship between $\mathrm{MC}$ accumulation in the $\mathrm{BM}$ and osteolytic bone disease in MM.

Our data suggest that MCs may contribute to osteolytic processes during MM progression. Although the major role of MCs in tumor progression is enhancing angiogenesis, it seems that they may also participate, mainly indirectly, in the unique MM bone disease, through both promotion of angiogenesis and secretion of various mediators. By these means it seems that MCs participate in the complex interplay of MM progression.

\section{Disclosure Statement}

We declare that there is no conflict of interest.

\section{References}

1 Oranger A, Carbone C, Izzo M, Grano M: Cellular mechanisms of multiple myeloma bone disease. Clin Dev Immunol 2013;2013: 289458.

2 Reagan MR, Liaw L, Rosen CJ, Ghobrial IM: Dynamic interplay between bone and multiple myeloma: emerging roles of the osteoblast. Bone 2015;75:161-169.

3 Ria R, Reale A, De Luisi A, Ferrucci A, Moschetta $\mathrm{M}$, Vacca A: Bone marrow angiogenesis and progression in multiple myeloma. Am J Blood Res 2011;1:76-89.

4 de Souza DA Jr, Santana AC, da Silva EZ, Oliver C, Jamur MC: The role of mast cell specific chymases and tryptases in tumor angiogenesis. Biomed Res Int 2015;2015:142359.

5 Pappa CA, Tsirakis G, Roussou P, Xekalou A, Goulidaki N, Konsolas I, Alexandrakis MG, Stathopoulos EN: Positive correlation between bone marrow mast cell density and ISS prognostic index in patients with multiple myeloma. Leuk Res 2013;37:1628-1631.

6 Pappa CA, Tsirakis G, Stavroulaki E, Kokonozaki M, Xekalou A, Konsolas I, Alexandrakis MG: Mast cells influence the proliferation rate of myeloma plasma cells. Cancer Invest 2015;33:137-141.

7 Ribatti D, Vacca A, Nico B, Quondamatteo F, Ria R, Minischetti M, Marzullo A, Herken R, Roncali L, Dammacco F: Bone marrow angiogenesis and mast cell density increase si- multaneously with progression of human multiple myeloma. Br J Cancer 1999;79:451455.

8 Ribatti D, Crivellato E, Roccaro AM, Ria R, Vacca A: Mast cell contribution to angiogenesis related to tumour progression. Clin Exp Allergy 2004;34:1660-1664.

9 Nico B, Mangieri D, Crivellato E, Vacca A, Ribatti D: Mast cells contribute to vasculogenic mimicry in multiple myeloma. Stem Cells Dev 2008;17:19-22.

10 Theoharides TC, Valent P, Akin C: Mast cells, mastocytosis, and related disorders. $\mathrm{N}$ Engl J Med 2015;373:163-172.

11 Theoharides TC, Petra AI, Stewart JM, Tsilioni I, Panagiotidou S, Akin C: High serum corticotropin-releasing hormone $(\mathrm{CRH})$ and bone marrow mast cell CRH receptor expression in a mastocytosis patient. J Allergy Clin Immunol 2014;134:1197-1199.

12 Ito N, Sugawara K, Bodó E, Takigawa M, van Beek N, Ito T, Paus R: Corticotropin-releasing hormone stimulates the in situ generation of mast cells from precursors in the human hair follicle mesenchyme. J Invest Dermatol 2010; 130:995-1004.

13 Enoksson M, Lyberg K, Möller-Westerberg C, Fallon PG, Nilsson G, Lunderius-Andersson C: Mast cells as sensors of cell injury through IL-33 recognition. J Immunol 2011;186: 2523-2528.
14 Theoharides TC, Petra AI, Taracanova A, Panagiotidou S, Conti P: Targeting IL-33 in autoimmunity and inflammation. J Pharmacol Exp Ther 2015;354:24-31.

15 Metcalfe DD: Mast cells and mastocytosis Blood 2008;112:946-956.

16 Pejler G, Abrink M, Ringvall M, Wernersson S: Mast cell proteases. Adv Immunol 2007;95: 167-255.

17 Galli SJ, Kalesnikoff J, Grimbaldeston MA, Piliponsky AM, Williams CM, Tsai M: Mast cells as 'tunable' effector and immunoregulatory cells: recent advances. Annu Rev Immunol 2005;23:749-786.

18 Galli SJ, Tsai M: Mast cells: versatile regulators of inflammation, tissue remodeling, host defense and homeostasis. J Dermatol Sci 2008;49:7-19.

19 Theoharides TC, Alysandratos KD, Angelidou A, Delivanis DA, Sismanopoulos N, Zhang B, Asadi S, Vasiadi M, Weng Z, Miniati A, Kalogeromitros D: Mast cells and inflammation. Biochim Biophys Acta 2012; 1822:21-33.

20 Ribatti D, Vacca A: The role of inflammatory cells in angiogenesis in multiple myeloma. Adv Exp Med Biol 2014;816:361-376.

21 Stockmann C, Schadendorf D, Klose R, Helfrich I: The impact of the immune system on tumor: angiogenesis and vascular remodeling. Front Oncol 2014;4:69. 
22 Brown JK, Tyler CL, Jones CA, Ruoss SJ, Hartmann T, Caughey GH: Tryptase, the dominant secretory granular protein in human mast cells, is a potent mitogen for cultured dog tracheal smooth muscle cells. Am J Respir Cell Mol Biol 1995;13:227-236.

23 Cairns JA, Walls AF: Mast cell tryptase is a mitogen for epithelial cells. Stimulation of IL-8 production and intercellular adhesion molecule-1 expression. J Immunol 1996;156: 275-283.

24 Theoharides TC, Boucher W, Spear K: Serum interleukin-6 reflects disease severity and osteoporosis in mastocytosis patients. Int Arch Allergy Immunol 2002;128:344-350.
25 Fukushima N, Satoh T, Sano M, Tokunaga O: Angiogenesis and mast cell in non-Hodgkin's lymphoma: a strong correlation in angioimmunoblastic T-cell lymphoma. Leuk Lymphoma 2001;42:709-720.

26 Shaik-Dasthagirisaheb YB, Varvara G, Murmura G, Saggini A, Potalivo G, Caraffa A, Antinolfi P, Tete' S, Tripodi D, Conti F, Cianchetti E, Toniato E, Rosati M, Conti P, Speranza L, Pantalone A, Saggini R, Theoharides TC, Pandolfi F: Vascular endothelial growth factor (VEGF), mast cells and inflammation. Int J Immunopathol Pharmacol 2013;26:327335.

27 Anderson KC: Multiple myeloma: a clinical overview. Oncology (Williston Park) 2011; 25(suppl 2):3-9.
28 Arock M, Akin C, Hermine O, Valent P: Current treatment options in patients with mastocytosis: status in 2015 and future perspectives. Eur J Haematol 2015;94:474-490.

29 Terpos E, Dimopoulos MA, Sezer O, Roodman D, Abildgaard N, Vescio R, Tosi P, Garcia-Sanz R, Davies F, Chanan-Khan A, Palumbo A, Sonneveld P, Drake MT, Harousseau JL, Anderson KC, Durie BG; International Myeloma Working Group: The use of biochemical markers of bone remodeling in multiple myeloma: a report of the International Myeloma Working Group. Leukemia 2010;24:1700-1712. 